\title{
Matching-adjusted indirect treatment comparison in patients with radioiodine-refractory differentiated thyroid cancer
}

This article was published in the following Dove Press journal:

Comparative Effectiveness Research

20 April 2016

Number of times this article has been viewed

\author{
Gabriel Tremblay' \\ Tim Holbrook ${ }^{2}$ \\ Gary Milligan ${ }^{2}$ \\ Corey L Pelletier' \\ Petra Rietschel' \\ 'Eisai Inc, Woodcliff Lake, NJ, USA; \\ ${ }^{2}$ Adelphi Real World, Manchester, UK
}

Correspondence: Gabriel Tremblay Global Health Economics and HTA, Eisai Global Value and Access Unit; 155 Tice Boulevard,Woodcliff Lake, NJ 07677, USA $\mathrm{Tel}+\mid$ 20I 66I 4768

Fax + I 20I 94940 I I

Email Gabriel_Tremblay@eisai.com
Aims: Lenvatinib and sorafenib have been evaluated in separate Phase III placebo-controlled trials in patients with radioiodine-refractory differentiated thyroid cancer; however, no head-tohead comparative studies are available. We performed an indirect comparison of these agents using matching-adjusted indirect comparison (MAIC) to adjust for differences in baseline characteristics, a technique allowing comparison of two studies with patient-level data available for one but only aggregate data available for the other.

Patients and methods: Individual patient data were available for the SELECT trial (lenvatinib versus placebo) whereas only published summary data were available for the DECISION trial (sorafenib versus placebo); therefore the SELECT data were adjusted to closely match the DECISION data. Data for patients in SELECT were assigned weights so that weighted mean baseline characteristics of the SELECT population matched those reported for DECISION. Adjusted hazard ratios (HRs) for progression-free survival (PFS) and overall survival (OS; corrected for crossover using rank-preserving structural failure time models) were calculated using weighted Cox regression models. Adjusted HRs were used to calculate indirect HRs with 95\% confidence intervals (CIs).

Results: Indirect treatment comparison using unadjusted clinical trial data resulted in an HR for PFS of 0.36 (95\% CI 0.22-0.57) for lenvatinib versus sorafenib; MAIC resulted in an HR of 0.33 (95\% CI $0.20-0.53)$, suggesting a statistically significantly superior PFS for lenvatinib. The HR for crossover-corrected OS for lenvatinib versus sorafenib was 0.77 (95\% CI 0.44-1.35); MAIC resulted in an OS HR of 0.73 (95\% CI 0.40-1.35).

Conclusion: After adjusting for differences in baseline characteristics using MAIC, lenvatinib was associated with statistically significantly superior PFS compared with sorafenib in patients with radioiodine-refractory differentiated thyroid cancer. This suggests lenvatinib may provide superior efficacy compared with sorafenib for patients with radioiodine-refractory differentiated thyroid cancer.

Keywords: indirect comparison, lenvatinib, overall survival, progression-free survival, radioiodine-refractory, sorafenib

\section{Introduction}

An estimated 62,500 new cases of thyroid cancer will be diagnosed in the US in $2015 .{ }^{1}$ Most thyroid cancers are differentiated cancers that develop from thyroid follicular cells, including papillary and follicular cancers. Differentiated thyroid cancers are frequently asymptomatic for long periods of time and patients commonly present with a single nodule. ${ }^{2}$ Although thyroid nodules are relatively common and increase in incidence throughout life, thyroid cancer is uncommon, with a lifetime risk of approximately $1 \%$ in the US. ${ }^{3}$ 
Treatment for localized thyroid cancer consists of surgery, thyroid-stimulating hormone management, and radioactive iodine (radioiodine) ablation for distant metastases. ${ }^{2,4}$ A proportion of patients $(<5 \%)^{5}$ will have disease that is refractory to radioiodine ablation therapy. Radioiodine-refractory differentiated thyroid cancer (RR-DTC) is difficult to treat and life-threatening. ${ }^{6}$ The 10 -year survival rate from the time of metastasis detection is only $10 \%$ in patients with RR-DTC compared with $56 \%$ in those responsive to radioiodine. ${ }^{7}$

Recent developments in our understanding of the processes underlying thyroid cancer have led to the investigation of tyrosine kinase inhibitors (TKIs) as treatment for RR-DTC. Phase III placebo-controlled trials in patients with RR-DTC have assessed the efficacy of the TKIs sorafenib ${ }^{8,9}$ and lenvatinib. ${ }^{10}$ Both of these studies demonstrated a significant progression-free survival (PFS) advantage for patients treated with the TKI. To date, however, no head-to-head Phase III studies have compared lenvatinib and sorafenib.

Determining the value of therapeutic agents is becoming more important in the context of limited health care budgets, an aging population, and increasing costs of new drugs. In an attempt to help guide decision-making at various levels, ranging from public policy to clinical practice, the European Society for Medical Oncology has developed a Magnitude of Clinical Benefit Scale that will score and derive relative rankings for new agents and interventions. ${ }^{11}$ This tool can only be applied to comparative studies. In a related initiative, the American Society of Clinical Oncology has developed a framework for comparing the relative clinical benefit of treatment, with the aim of helping physicians and patients assess the value of a new drug versus a standard of care. ${ }^{12}$ Within this framework, the net health benefit (NHB; a combination of clinical benefit and toxicity) of an agent is derived from randomized clinical trials comparing two or more chemotherapy regimens. This NHB is limited to therapies compared within a clinical trial and one NHB is not comparable with the NHB of other regimens determined on the basis of a different comparator regimen used in another trial.

In the absence of comparative data from head-to-head clinical studies, indirect treatment comparison based on available placebo-controlled studies is one possible option for health care decision-makers. Network meta-analysis can also be used to facilitate cross-trial comparisons. However, indirect treatment comparison approaches are limited by differences in characteristics of the studies being compared, such as study design and patient characteristics, which can bias the results. These limitations are especially pronounced when the number of studies is small. ${ }^{13}$ Matching-adjusted indirect comparison (MAIC) is a technique that has been developed to allow for the comparison of two studies, while controlling for baseline characteristics, when individual patient data are available for only one study. ${ }^{13}$ In this approach, the population with individual patient data is adjusted and reweighted to match the population with summary statistical data. Treatment outcomes can then be compared between the two groups. This approach has been used to provide comparative evidence in advance of the publication of randomized comparative studies in several settings, including chronic myeloid leukemia, attention-deficit hyperactivity disorder, diabetes, and psoriatic arthritis. ${ }^{14-18}$

We used MAIC in the present analysis to compare the efficacy of lenvatinib and sorafenib in patients with RR-DTC based on data from the only two randomized controlled studies currently available for these agents: patient-level data from the SELECT trial ${ }^{10}$ and aggregate data from the DECISION trial. ${ }^{8,9}$

\section{Methods}

\section{Study designs}

Evidence of the efficacy of lenvatinib and sorafenib in patients with RR-DTC has been demonstrated in two separate pivotal Phase III studies. Lenvatinib (Eisai Inc, Woodcliff Lake, NJ, USA; $24 \mathrm{mg}$ /day in 28-day cycles) was compared with placebo in the multicenter SELECT trial ${ }^{10}$ and sorafenib (Bayer AG, Leverkusen, Germany; 400 mg twice daily) was compared with placebo in the multicenter DECISION trial. ${ }^{8}$ Design features of both studies and differences between them are summarized in Table 1.

Crossover was permitted on progression in both studies. In SELECT, placebo-treated patients with progressive disease confirmed by independent review could elect to enter the open-label lenvatinib phase. In DECISION and SELECT, treatment could be unmasked in patients with protocol-defined, investigator-determined disease progression (confirmed by central independent blinded review) and the patient could begin open-label sorafenib or lenvatinib, respectively.

\section{Outcome measures}

The primary endpoint in both studies was PFS. ${ }^{8,10}$ PFS in SELECT was defined as the time from randomization to the first documentation of disease progression by independent radiological review or to death in the intention-to-treat population (all patients who underwent randomization). PFS in DECISION was defined as the time from randomization to radiological progression or death. Overall survival (OS) was a secondary endpoint in both studies and was defined as the time from randomization to death. 
For the DECISION trial, PFS data (median values and hazard ratios [HRs]) were extracted from published data on the primary analysis, which was performed on August 31, 2012, when 240 PFS events had occurred. ${ }^{8}$ At that cut-off, median OS had not been reached; however, results of an updated OS analysis have since been published based on a data cut-off on May 31, 2013. ${ }^{9}$

Individual patient data were available for the SELECT study. PFS data for the SELECT trial were obtained at the protocol-defined cut-off date for the primary analysis (November 15, 2013), at which point the median OS had not been reached; an updated OS analysis, requested by the European Medicines Authority, was performed when more mature and informative OS data were available (June 15, 2014). ${ }^{19}$

For the present analysis, therefore, the following datacuts were used: DECISION: PFS data were taken from the primary analysis ${ }^{8}$ and OS data were obtained from the updated survival analysis 9 ; SELECT: PFS data were obtained from the primary analysis ${ }^{10}$ and OS data were obtained from the updated survival analysis. ${ }^{19}$ In both studies, crossover-corrected OS data were also available for comparison. In the SELECT updated analysis, the 95\% confidence interval (CI) and $P$-value for the OS HR were estimated using a resampling method (bootstrapping). ${ }^{19}$

\section{Statistical methods}

For both PFS and OS, SELECT data were first matched and adjusted to the DECISION data to ensure comparability of the two datasets. An adjusted HR was then calculated for SELECT and this adjusted HR was used to calculate a matched-adjusted HR comparing the PFS for lenvatinib-treated patients with the PFS for those treated with sorafenib.

The first step in the matching process involved aligning the inclusion/exclusion criteria for the two datasets as closely as possible by modifying the SELECT population. As brain metastases and previous treatment with targeted therapies for thyroid cancer were exclusion criteria in the DECISION trial, patients fulfilling these criteria were removed from the SELECT population.

The second step involved weighting the SELECT data such that the means/percentages of patient characteristics common to both datasets matched those in DECISION. Characteristics used in the matching process were age, sex, Eastern Cooperative Oncology Group performance status, geographical region, histology, and site of metastasis. The weight was created by performing a logistic regression on the patient-level SELECT data that included an extra observation (patient) representing the DECISION data, ie,

Table I Study characteristics

\begin{tabular}{|c|c|c|c|}
\hline Characteristic & DECISION trial ${ }^{8}$ & SELECT trial ${ }^{10}$ & Differences between trials \\
\hline $\begin{array}{l}\text { Definition of } \\
\text { "radioactive } \\
\text { iodine-refractory" }\end{array}$ & $\begin{array}{l}\geq \mathrm{I} \text { target lesion without iodine uptake; or } \\
\text { patients whose tumors had iodine uptake } \\
\text { and either progressed after one radioactive } \\
\text { iodine treatment within the past } 16 \text { months, } \\
\text { or progressed after two radioactive iodine } \\
\text { treatments within } 16 \text { months of each other } \\
\text { (last treatment administered }>16 \text { months } \\
\text { ago), or received cumulative radioactive } \\
\text { iodine activity of } \geq 22.3 \mathrm{GBq} \text { ( } \geq 600 \mathrm{mCi} \text { ) }\end{array}$ & $\begin{array}{l}\geq \text { I measurable lesions without } \\
\text { iodine uptake; } \geq \text { I measurable lesions } \\
\text { that progressed by RECIST } \vee \text { I.I } \\
\text { within I } 2 \text { months of }{ }^{|3|} \mid \text { therapy; } \\
\text { not eligible for possible curative } \\
\text { surgery. Cumulative }{ }^{|3|} \mid \text { activity } \\
\text { of }>600 \text { mCi or } 22 \mathrm{GBq} \text {, last } \\
\text { dose administered } \geq 6 \text { months } \\
\text { before study entry }\end{array}$ & None \\
\hline $\begin{array}{l}\text { Definition of } \\
\text { "progression" }\end{array}$ & $\begin{array}{l}\text { Disease that had progressed within the } \\
\text { past } 14 \text { months according to RECIST } \vee 1.0\end{array}$ & $\begin{array}{l}\text { Evidence of disease progression } \\
\text { within } 12 \text { months prior to signing } \\
\text { informed consent (+I month } \\
\text { screening window) }\end{array}$ & $\begin{array}{l}\text { Not identical but sufficient for } \\
\text { comparison. In DECISION, investigators } \\
\text { confirmed progression }\end{array}$ \\
\hline Inclusion criteria & $\begin{array}{l}\text { Progression (per modified RECIST } \vee \mathrm{I} .0 \text { ) } \\
\text { in the } 14 \text { months prior to study entry; } \\
\text { age } \geq 18 \text { years; no prior targeted therapy }\end{array}$ & $\begin{array}{l}\text { Progression (per RECIST } v \text { I.I) in } \\
\text { the I } 2 \text { months (+I month window) } \\
\text { before study entry confirmed by } \\
\text { independent imaging review; } \\
\text { age } \geq 18 \text { years; } \leq \text { I prior } \\
\text { VEGF/VEGFR-targeted therapy }\end{array}$ & $\begin{array}{l}\text { Similar inclusion criteria (I } 2 / 13 \text { months } \\
\text { versus } 14 \text { months). SELECT required } \\
\text { independent review of inclusion criteria, } \\
\text { resulting in high rate of screening failures. } \\
\text { Patients included in SELECT may have } \\
\text { had more severe cancer, as prior VEGF/ } \\
\text { VEGFR-targeted therapy was allowed }\end{array}$ \\
\hline Measurement of PS & ECOG PS 0-2 & ECOG PS 0-2 & None \\
\hline Tumor histology & $\begin{array}{l}\text { Papillary, follicular, or poorly } \\
\text { differentiated thyroid cancer }\end{array}$ & $\begin{array}{l}\text { Papillary, follicular or poorly } \\
\text { differentiated thyroid cancer }\end{array}$ & None \\
\hline Tumor assessment & $\begin{array}{l}\text { CT or MRI scan every } 8 \text { weeks followed } \\
\text { by assessment by central independent } \\
\text { blinded review using RECIST v I.0 }\end{array}$ & $\begin{array}{l}\text { CT or MRI scan every } 8 \text { weeks } \\
\text { followed by assessment by central } \\
\text { imaging laboratory using RECIST } \vee \text { I.I }\end{array}$ & $\begin{array}{l}\text { RECIST versions are slightly different; } \\
\text { however, the approach is the same }\end{array}$ \\
\hline
\end{tabular}

Abbreviations: CT, computed tomography; ECOG, Eastern Cooperative Oncology Group; MRI, magnetic resonance imaging; PS, performance status; RECIST, Response Evaluation Criteria in Solid Tumors; TKI, tyrosine kinase inhibitor; v, version; VEGF (R), vascular endothelial growth factor (receptor); ${ }^{131}$ I, iodine I3I. 
a patient to whom the mean/percentage summarized values for the DECISION patient characteristics were attributed. The predicted values (or propensity score) that resulted from the logistic regression were used to weight the SELECT data, ie, adjusted HRs were calculated using weighted Cox regression models.

A large proportion of patients in both studies $(75 \%$ in DECISION and $88 \%$ in SELECT) crossed over from placebo to TKI treatment upon disease progression, resulting in a loss of information on the magnitude of the clinical effect of treatment in the absence of crossover and a biased estimate of OS. In both studies, OS data corrected for crossover using rank-preserving structural failure time models ${ }^{20}$ were available for comparison.

For each of the comparisons above (PFS and crossovercorrected OS), a further comparison was made that excluded the matching process. Thus, there were four comparisons in total: PFS indirect comparison; PFS MAIC; OS crossovercorrected indirect comparison; and OS crossover-corrected MAIC.

Analyses were conducted using Stata (version 13.1; StataCorp LP, College Station, TX, USA).

Table 2 Baseline demographic and clinical characteristics in the SELECT and DECISION trials

\begin{tabular}{|c|c|c|c|c|}
\hline \multirow[t]{2}{*}{ Characteristic } & \multicolumn{2}{|l|}{ SELECT trial ${ }^{10}$} & \multicolumn{2}{|l|}{ DECISION trial ${ }^{8}$} \\
\hline & Lenvatinib $(\mathbf{N}=\mathbf{2 6} \mathrm{I})$ & Placebo $(\mathbf{N}=|3|)$ & Sorafenib ( $\mathbf{N}=\mathbf{2 0 7})$ & Placebo $(\mathbf{N}=2 \mid 0)$ \\
\hline Median age (range), years & 64 (27-89) & $6 I(2|-8|)$ & $63(24-82)$ & $63(30-87)$ \\
\hline \multicolumn{5}{|l|}{ Sex, n (\%) } \\
\hline Male & $125(48)$ & $75(57)$ & $104(50)$ & $95(45)$ \\
\hline Female & $136(52)$ & $56(43)$ & $103(50)$ & $115(55)$ \\
\hline \multicolumn{5}{|l|}{ Race, n (\%) } \\
\hline White & $208(80)$ & $103(79)$ & $125(60)$ & 130 (62) \\
\hline Black or African American & $4(2)$ & $4(3)$ & $6(3)$ & $5(2)$ \\
\hline Asian & $46(18)$ & $24(18)$ & $47(23)$ & $52(25)$ \\
\hline Other & $3(1)$ & 0 & 0 & 0 \\
\hline Not reported & 0 & 0 & $29(14)$ & $23(\mathrm{II})$ \\
\hline \multicolumn{5}{|l|}{ ECOG performance status, $n(\%)$} \\
\hline 0 & I44 (55) & $68(52)$ & $130(63)$ & $129(6 \mathrm{I})$ \\
\hline 1 & $104(40)$ & $61(47)$ & $69(33)$ & $74(35)$ \\
\hline 2 & $12(5)$ & $2(2)$ & $7(3)$ & $6(3)$ \\
\hline 3 & $\mathrm{I}(<\mathrm{I})$ & 0 & 0 & 0 \\
\hline Not available & 0 & 0 & $\mathrm{I}(<\mathrm{I})$ & $\mathrm{I}(<\mathrm{I})$ \\
\hline \multicolumn{5}{|l|}{ Geographic region, n (\%) } \\
\hline Europe & $|3|(50)$ & $64(49)$ & $124(60)$ & $125(60)$ \\
\hline North America & $77(30)$ & $39(30)$ & $36(17)$ & $36(17)$ \\
\hline Other/Asia & $53(20)$ & $28(2 I)$ & $47(23)$ & $49(23)$ \\
\hline \multicolumn{5}{|l|}{ Histology, n (\%) } \\
\hline Papillary TC & $169(65)$ & $90(69)$ & $144(70)$ & $136(65)$ \\
\hline Follicular TC & $92(35)$ & $4 I(3 I)$ & $50(24)$ & $56(27)$ \\
\hline Other & 0 & 0 & $15(7)$ & $17(8)$ \\
\hline Thyroid surgery, n (\%) & $261(100)$ & $|3|(100)$ & $207(100)$ & $208(99)$ \\
\hline Locally advanced disease, n (\%) & $4(2)$ & 0 & $7(3)$ & $7(3)$ \\
\hline Metastatic disease, n (\%) & $257(99)$ & $131(100)$ & $200(97)$ & $203(97)$ \\
\hline \multicolumn{5}{|l|}{ Site of metastasis, $\mathrm{n}(\%)$} \\
\hline Lung & $226(87)$ & $124(95)$ & $178(86)$ & I8I (86) \\
\hline Lymph nodes & $138(53)$ & $64(49)$ & II3 (55) & $101(48)$ \\
\hline Bone & $104(40)$ & $48(37)$ & $57(28)$ & $56(27)$ \\
\hline Pleura & $46(18)$ & $18(14)$ & $40(19)$ & $24(\mathrm{II})$ \\
\hline Liver & $43(17)$ & $28(2 I)$ & $28(14)$ & $30(14)$ \\
\hline Head and neck & NA & NA & $33(16)$ & $34(16)$ \\
\hline Brain & $9(3)$ & $7(5)$ & NA & NA \\
\hline Prior VEGF/VEGFR-targeted therapy, n (\%) & $66(25)$ & $27(2 \mathrm{I})$ & NA & NA \\
\hline
\end{tabular}

Notes: From N Engl J Med. Schlumberger M, Tahara M, Wirth LJ, et al. Lenvatinib versus placebo in radioiodine-refractory thyroid cancer. 372(7):62I-630. Copyright $\odot ~ 2015$ Massachusetts Medical Society. Reprinted with permission from Massachusetts Medical Society. ${ }^{10}$ Reprinted from Lancet. Vol 384(9940). Brose MS, Nutting CM, Jarzab B, et al. Sorafenib in radioactive iodine-refractory, locally advanced or metastatic differentiated thyroid cancer: a randomised, double-blind, phase 3 trial. Pages 319-328., Copyright 2014, with permission from Elsevier. ${ }^{8}$

Abbreviations: ECOG, Eastern Cooperative Oncology Group; NA, not applicable; TC, thyroid cancer; VEGF, vascular endothelial growth factor; VEGFR, vascular endothelial growth factor receptor. 
Table 3 Key patient characteristics before and after adjustment

\begin{tabular}{|c|c|c|c|}
\hline \multirow[t]{2}{*}{ Characteristic } & \multirow{2}{*}{$\begin{array}{l}\text { DECISION } \\
\text { trial }^{\mathrm{a}}\end{array}$} & \multicolumn{2}{|c|}{ SELECT trial ${ }^{\mathrm{b}}$} \\
\hline & & $\begin{array}{l}\text { Without } \\
\text { weights }\end{array}$ & $\begin{array}{l}\text { With } \\
\text { weights }\end{array}$ \\
\hline Median age, years & 63.00 & 62.10 & 63.00 \\
\hline Male, \% & 48 & 51 & 48 \\
\hline White, $\%$ & 70 & 77 & 70 \\
\hline $\begin{array}{l}\text { ECOG performance } \\
\text { status, mean }\end{array}$ & 0.41 & 0.48 & $0.4 I$ \\
\hline \multicolumn{4}{|l|}{ Geographic region, \% } \\
\hline Europe & 60 & 48 & 60 \\
\hline North America & 17 & 27 & 17 \\
\hline Histology - papillary TC, \% & 67 & 65 & 67 \\
\hline Metastatic disease, \% & 97 & 99 & 97 \\
\hline \multicolumn{4}{|l|}{ Site of metastasis, $\%$} \\
\hline Lung & 86 & 91 & 86 \\
\hline Lymph nodes & 51 & 46 & 51 \\
\hline Bone & 27 & 35 & 27 \\
\hline Pleura & 15 & 15 & 15 \\
\hline Liver & 14 & 19 & 14 \\
\hline
\end{tabular}

Notes: ${ }^{\mathrm{D} D a t a}$ adapted from Brose et al. ${ }^{8}$ Data adapted from Schlumberger et al..$^{10}$ Abbreviations: ECOG, Eastern Cooperative Oncology Group; TC, thyroid cancer.

\section{Results \\ Patients}

The designs of the SELECT and DECISION studies were generally comparable, although some differences were noted (Table 1).

The median follow-up time in the SELECT trial was 17.1 and 17.4 months for the lenvatinib and placebo arms, respectively, for the primary analysis and 23.6 and 24.1 months, respectively, for the updated OS analysis. The median follow-up time in the DECISION trial was 16.2 months for the primary analysis.

In the SELECT trial, the intention-to-treat population comprised 261 patients treated with lenvatinib and 131 treated with placebo. The intention-to-treat population in DECISION consisted of 207 patients treated with sorafenib and 209 treated with placebo. Patient characteristics are summarized in Table 2. Geographical distribution of patients and the proportion of patients with bone metastases differed between the two studies. After matching adjustment, means and percentages for patient characteristics common to both studies were matched (Table 3).

\section{PFS}

In the SELECT trial, lenvatinib treatment resulted in a median PFS of 18.3 months (95\% CI 15.1 months-not estimable); median PFS in sorafenib-treated patients in DECISION was 10.8 months. The median PFS for the placebo arm was shorter in the lenvatinib trial than in the sorafenib trial (3.6 versus 5.8 months, respectively). In both studies, the active treatment provided a statistically significant prolongation of median PFS compared with placebo.

Results of the indirect treatment comparison analyses of PFS for lenvatinib versus placebo and sorafenib versus placebo are summarized in Table 4. Unadjusted HRs were 0.21 (95\% CI 0.14-0.31) for lenvatinib versus placebo and 0.59 (95\% CI 0.45-0.76) for sorafenib versus placebo. MAIC resulted in an HR of 0.19 (95\% CI 0.13-0.29) for lenvatinib versus placebo (Figure 1A).

Results of the indirect treatment comparison of PFS for lenvatinib versus sorafenib are shown in Figure 1B and summarized in Table 4. The HR for PFS for the unadjusted clinical trial data was 0.36 (95\% CI 0.22-0.57) for lenvatinib versus sorafenib; following MAIC, the HR for lenvatinib versus sorafenib was 0.33 (95\% CI 0.20-0.53) (Figure 1B).

\section{OS}

Median OS had not been reached in either of the activetreatment arms in SELECT and DECISION at the time of the updated analyses (Table 4). The crossover-corrected HRs for OS were 0.53 (95\% CI 0.34-0.82) for lenvatinib versus placebo and 0.69 (95\% CI 0.49-0.99) for sorafenib versus placebo. Applying MAIC to the crossover-corrected OS for lenvatinib versus placebo resulted in an $\mathrm{HR}$ of $0.51(95 \% \mathrm{CI}$ 0.30-0.82) (Figure 2A).

Table 4 Comparison of PFS and OS data before and after matching

\begin{tabular}{|c|c|c|c|}
\hline \multirow[t]{2}{*}{ Data set } & \multicolumn{3}{|l|}{ HR $(95 \% \mathrm{Cl})$} \\
\hline & Lenvatinib versus placebo & Sorafenib versus placebo & Lenvatinib versus sorafenib \\
\hline \multicolumn{4}{|l|}{ PFS } \\
\hline Unadjusted clinical trial data & $0.2 I(0 . \mid 4-0.31)^{\mathrm{a}}$ & $0.59(0.45-0.76)^{b}$ & $0.36(0.22-0.57)$ \\
\hline MAIC-adjusted data & $0.19(0.13-0.29)$ & NA & $0.33(0.20-0.53)$ \\
\hline \multicolumn{4}{|l|}{ OS } \\
\hline Clinical trial data & $0.80(0.57-1.12)^{c}$ & $0.88(0.63-1.24)^{d}$ & $0.91(0.57-1.46)$ \\
\hline Crossover-corrected data & $0.53(0.34-0.82)^{c}$ & $0.69(0.49-0.99)^{d}$ & $0.77(0.44-1.35)$ \\
\hline MAIC crossover-corrected data & $0.5 \mathrm{I}(0.30-0.82)$ & NA & $0.73(0.40-1.35)$ \\
\hline
\end{tabular}

Notes: ${ }^{\mathrm{a} D a t a}$ from Schlumberger et al. ${ }^{10}$ bata from Brose et al. ${ }^{8}$ Cupdated survival analysis (data from Guo et al)..$^{19}$ dupdated survival analysis (data from Brose et al. $)^{9}$ NA indicates only aggregate data were available and these were not subjected to MAIC.

Abbreviations: $\mathrm{Cl}$, confidence interval; $\mathrm{HR}$, hazard ratio; MAIC, matching-adjusted indirect comparison; $\mathrm{NA}$, not applicable; OS, overall survival; PFS, progression-free survival. 
A
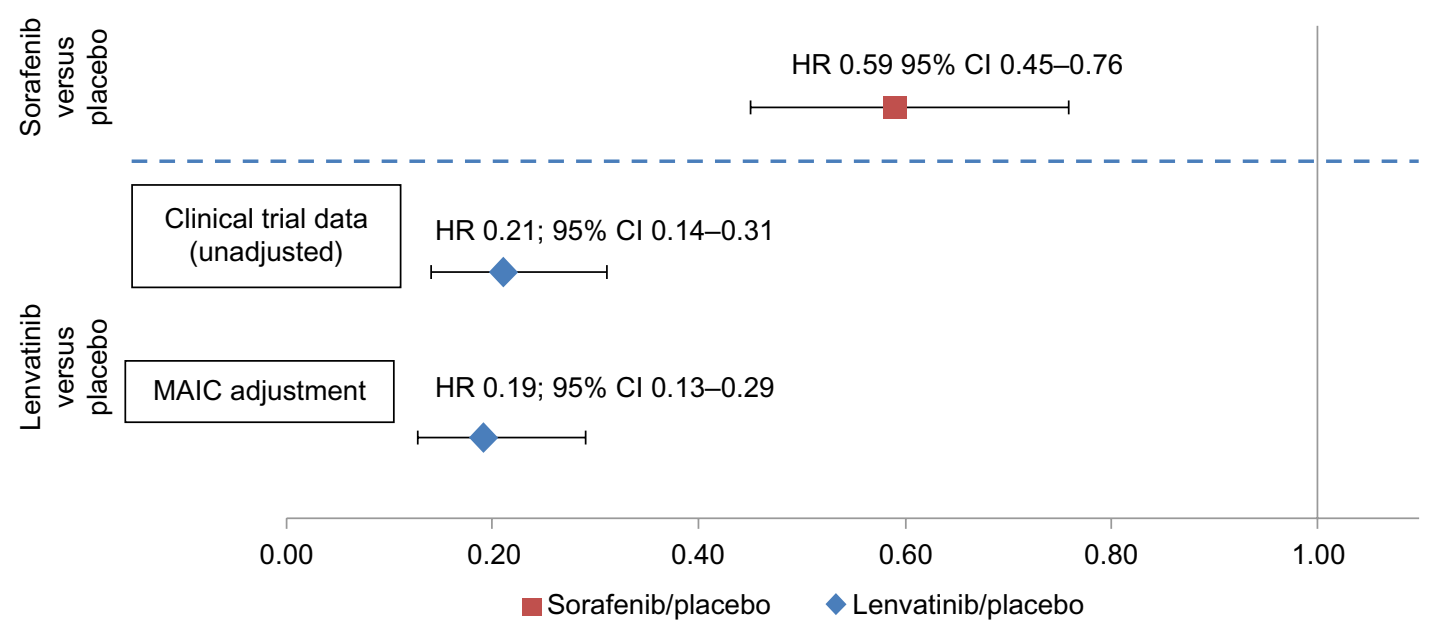

B

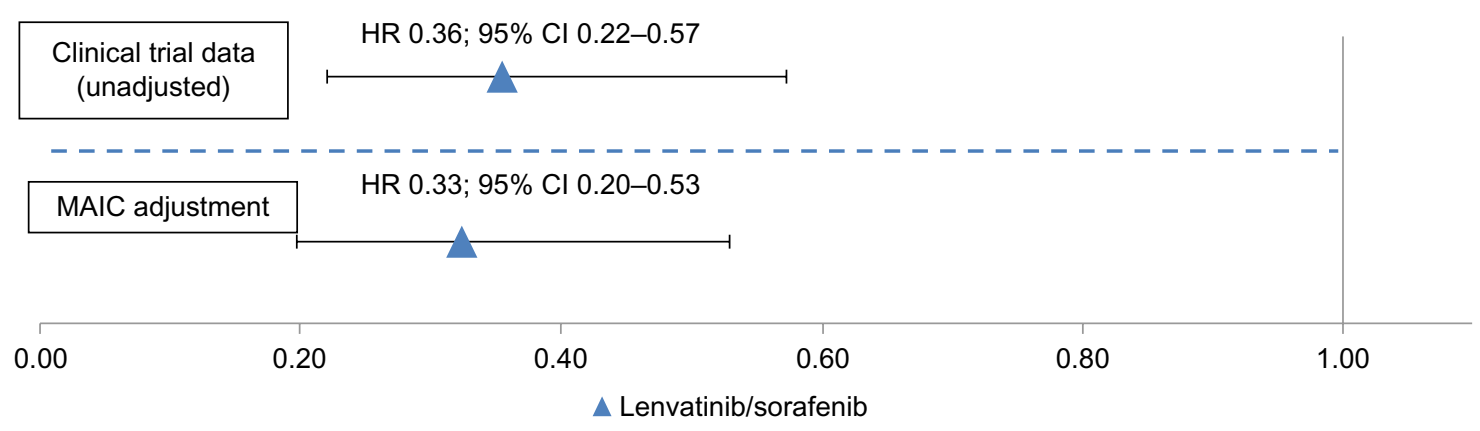

Figure I Comparison of PFS for (A) lenvatinib (and sorafenib) versus placebo and (B) lenvatinib versus sorafenib.

Abbreviations: $\mathrm{Cl}$, confidence interval; HR, hazard ratio; MAIC, matching-adjusted indirect comparison; PFS, progression-free survival.

Indirect treatment comparison of unadjusted clinical trial data resulted in an HR for OS of 0.91 (95\% CI 0.57-1.46) for lenvatinib versus sorafenib. Using crossover-corrected OS data for lenvatinib versus sorafenib resulted in an HR of 0.77 (95\% CI 0.44-1.35). Applying MAIC to the crossovercorrected data resulted in an HR of 0.73 (95\% CI 0.40-1.35) (Table 4; Figure 2B).

\section{Discussion}

RR-DTC is an orphan disease in which few large-scale randomized clinical trials have been conducted. Importantly, no head-to-head clinical studies comparing lenvatinib and sorafenib have been carried out in this patient population, leaving decision-makers unable to apply best-available evidence to newly emerging value frameworks. To generate comparative evidence of treatment effect in the absence of head-to-head studies, we used the MAIC approach to compare results from the SELECT trial, for which individual patient-level data were available, and the DECISION trial, for which only aggregate data were available, adjusting baseline characteristics of the SELECT population to match those of the DECISION population.

Our analysis of PFS after MAIC revealed a statistically significant PFS advantage for lenvatinib compared with sorafenib for patients with RR-DTC. This benefit was notable because SELECT patients had more severe disease than those in DECISION, including a higher prevalence of bone metastases, which has been associated with poor survival in patients with thyroid cancer. ${ }^{21,22}$

After adjusting for baseline differences using MAIC and correcting for crossover, lenvatinib appeared to be associated with better OS than sorafenib in RR-DTC, although the observed difference was not statistically significant. OS data may still be confounded by post-progression crossover from placebo to active treatment (even though rank-preserving structural failure time model was applied), sample size (neither study was powered to demonstrate a difference in OS compared with placebo), and incomplete OS data. In 


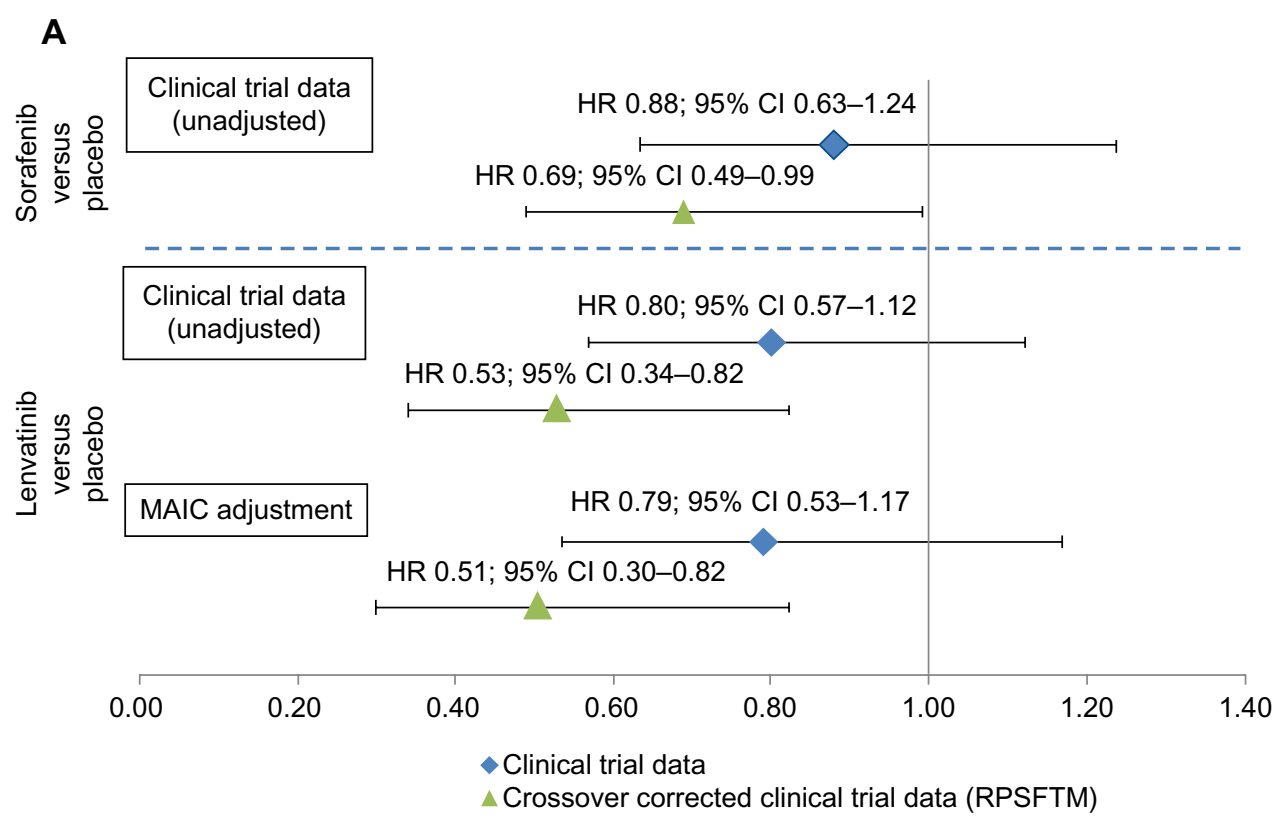

B

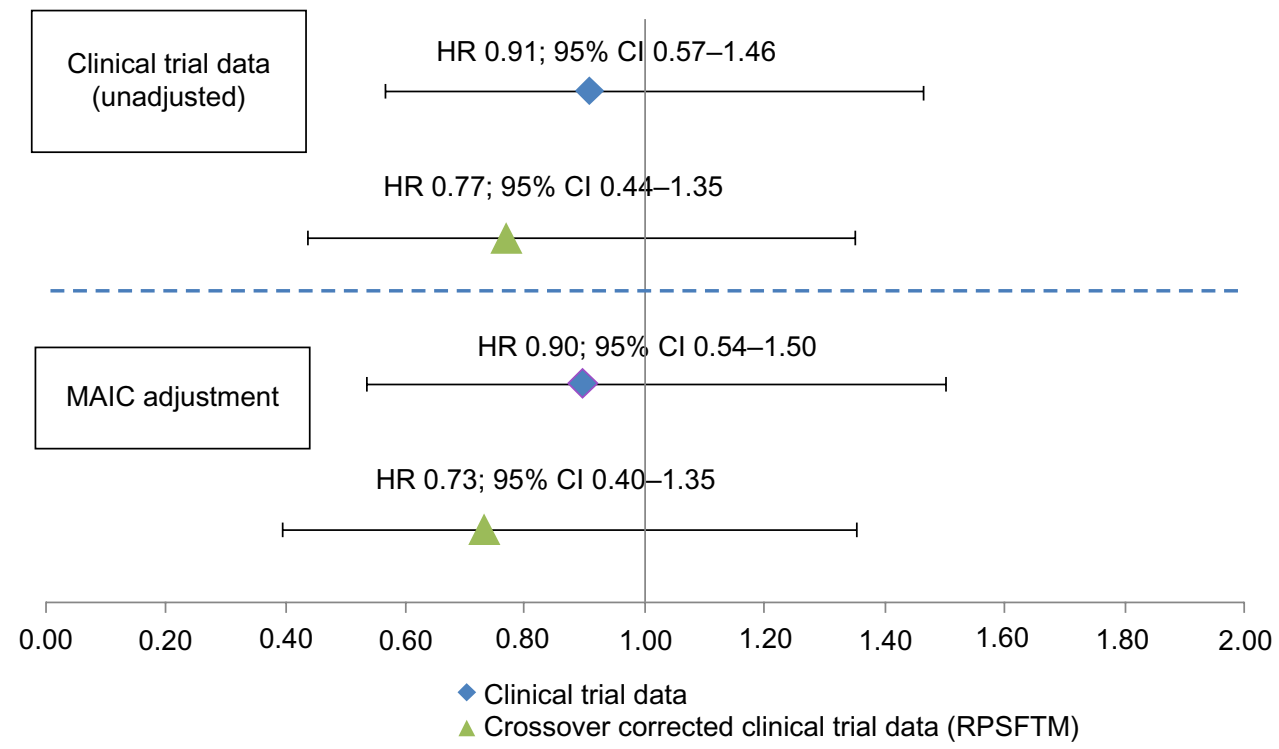

Figure 2 Comparison of OS for (A) lenvatinib versus placebo and sorafenib versus placebo and (B) lenvatinib versus sorafenib.

Abbreviations: $\mathrm{Cl}$, confidence interval; HR, hazard ratio; MAIC, matching-adjusted indirect comparison; OS, overall survival; RPSFTM, rank-preserving structural failure time model.

the absence of mature data for OS, PFS findings provide the best-available indicator of comparative treatment-effect superiority.

Recently proposed systems developed by the American Society of Clinical Oncology and the European Society for Medical Oncology that aim to assess and compare the benefits provided by a therapeutic intervention place considerable emphasis on evidence obtained from randomized studies comparing one active agent with another, such as standard of care. ${ }^{11,12}$ Although this is the ideal situation, such trials are not always feasible, eg, where the potentially eligible sample sizes are small due to the limited prevalence of a disease. Consequently, other approaches have been considered, such as examining the absolute benefit of a given therapy (eg, assigning a score based on absolute months of survival achieved) instead of the relative benefit observed in a study; however, between-study differences in patient populations may lead to incorrect conclusions from this approach. Another limitation is that the study population is defined by eligibility criteria and is unlikely to match either the patient population included 
in another study or indeed the general cancer population. In such instances, MAIC may be a valid alternative, filling the evidence gap and providing decision-makers with evidence to input into frameworks that are likely to become a significant part of the decision-making process. The MAIC process is based on HRs obtained from populations rendered comparable by focusing on inclusion criteria common to the studies in question and by minimizing design bias that might otherwise result from cross-trial comparisons.

Some limitations of this analysis should be considered. Only patient characteristics common to both studies and reported in DECISION were matched; other unobserved factors may therefore have influenced the results. The exclusion from this analysis of patients previously treated with VEGFtargeted therapies limits our conclusions to patients who have not received prior treatment with these agents.

In conclusion, after adjusting for observed differences between the SELECT and DECISION trials in patients with RRDTC, lenvatinib was associated with statistically significantly longer PFS compared with sorafenib based on an MAIC of individual patient data from the SELECT trial and aggregate data from the DECISION trial. MAIC is an important methodology that adjusts for differences between patients and trials to allow cross-study comparisons to be performed, which is particularly valuable in orphan diseases where comparative data are limited. This analysis of the SELECT and DECISION trials may provide decision-makers with informative comparative effectiveness evidence in the absence of head-to-head studies and may be used as part of the decision framework in RR-DTC.

\section{Acknowledgment}

These data were presented in part at the 20th Annual Meeting of the International Society for Pharmacoeconomics and Outcomes Research, Philadelphia, PA, May 2015 (abstract PRM6).

\section{Disclosure}

GT, CP, and PR are employed by Eisai. TH and GM are employed by Adelphi Real World. The authors have no other conflicts of interest to declare.

\section{References}

1. Surveillance, Epidemiology, and End Results Program [homepage on the Internet]. SEER Stat Fact Sheets: Thyroid Cancer. SEER; 2015. Available from: http://seer.cancer.gov/statfacts/html/thyro.html. Accessed January $17,2016$.

2. National Comprehensive Cancer Network. National Comprehensive Cancer Network Clinical Practice Guidelines in Oncology (NCCN Guidelines $\left.^{\mathbb{Q}}\right)$. Thyroid carcinoma version 2.2015. Available from: http:// www.nccn.org/professionals/physician_gls/pdf/thyroid.pdf. Accessed January 17, 2016.
3. Howlader N, Noone AM, Krapcho M, et al, editors. SEER Cancer Statistics Review (CSR) 1975-2012. National Cancer Institute. Bethesda, MD. Available from: http://seer.cancer.gov/csr/1975_2012/. Accessed January 17, 2016.

4. Pacini F, Castagna MG, Brilli L, Pentheroudakis G; ESMO Guidelines Working Group. Thyroid cancer: ESMO Clinical Practice Guidelines for diagnosis, treatment and follow-up. Ann Oncol. 2012;23 Suppl 7:vii110-vii119.

5. Brose MS, Smit J, Capdevila J, et al. Regional approaches to the management of patients with advanced, radioactive iodine-refractory differentiated thyroid carcinoma. Expert Rev Anticancer Ther. 2012;12(9):1137-1147.

6. Schvartz C, Dalac A, Ancelle D, Pochart J, Fieffe S, Patey M. Epidemiology of refractory thyroid cancer. Thyroid. 2012;22:A109-A110.

7. Durante C, Haddy N, Baudin E, et al. Long-term outcome of 444 patients with distant metastases from papillary and follicular thyroid carcinoma: benefits and limits of radioiodine therapy. J Clin Endocrinol Metab. 2006;91(8):2892-2899.

8. Brose MS, Nutting CM, Jarzab B, et al. Sorafenib in radioactive iodine-refractory, locally advanced or metastatic differentiated thyroid cancer: a randomised, double-blind, phase 3 trial. Lancet. 2014;384(9940):319-328.

9. Brose MS, Jarzab B, Elisei R, et al. Updated overall survival analysis of patients with locally advanced or metastatic radioactive iodinerefractory differentiated thyroid cancer (RAI-rDTC) treated with sorafenib on the phase 3 DECISION trial. J Clin Oncol. 2014; 32(15 Suppl): abstr 6060 .

10. Schlumberger M, Tahara M, Wirth LJ, et al. Lenvatinib versus placebo in radioiodine-refractory thyroid cancer. $N$ Engl $J$ Med. 2015;372(7):621-630.

11. Cherny NI, Sullivan R, Dafni U, et al. A standardised, generic, validated approach to stratify the magnitude of clinical benefit that can be anticipated from anti-cancer therapies: the European Society for Medical Oncology Magnitude of Clinical Benefit Scale (ESMO-MCBS). Ann Oncol. 2015;26(8):1547-1573.

12. Schnipper LE, Davidson NE, Wollins DS, et al. American Society of Clinical Oncology Statement: A Conceptual Framework to Assess the Value of Cancer Treatment Options. J Clin Oncol. 2015;33(23):2563-2577.

13. Signorovitch J, Swallow E, Kantor E, et al. Everolimus and sunitinib for advanced pancreatic neuroendocrine tumors: a matching-adjusted indirect comparison. Exp Hematol Oncol. 2013;2(1):32.

14. Signorovitch JE, Sikirica V, Erder MH, et al. Matching-adjusted indirect comparisons: a new tool for timely comparative effectiveness research. Value Health. 2012;15(6):940-947.

15. Signorovitch JE, Betts KA, Reichmann WM, et al. One-year and longterm molecular response to nilotinib and dasatinib for newly diagnosed chronic myeloid leukemia: a matching-adjusted indirect comparison. Curr Med Res Opin. 2015;31(2):315-322.

16. Sikirica V, Findling RL, Signorovitch J, et al. Comparative efficacy of guanfacine extended release versus atomoxetine for the treatment of attention-deficit/hyperactivity disorder in children and adolescents: applying matching-adjusted indirect comparison methodology. CNS Drugs. 2013;27(11):943-953.

17. Signorovitch JE, Wu EQ, Swallow E, Kantor E, Fan L, Gruenberger JB. Comparative efficacy of vildagliptin and sitagliptin in Japanese patients with type 2 diabetes mellitus: a matching-adjusted indirect comparison of randomized trials. Clin Drug Investig. 2011;31(9):665-674.

18. Kirson NY, Rao S, Birnbaum HG, Kantor E, Wei RS, Cifaldi M. Matching-adjusted indirect comparison of adalimumab vs etanercept and infliximab for the treatment of psoriatic arthritis. J Med Econ. 2013;16(4):479-489.

19. Guo M, Sherman S, Wirth L, et al. Overall survival gain with lenvatinib vs placebo in radioactive iodine refractory differentiated thyroid cancer (RR-DTC): an updated analysis. Abstract 2805 presented at the European Cancer Congress; September 25-29, 2015; Vienna, Austria. Available from: http://www.europeancancercongress.org/Scientific-Programme/ Abstract-search?abstractid=21093. Accessed January 17, 2016. 
20. Robins JM, Tsiatis AA. Correcting for non-compliance in randomized trials using rank preserving structural failure time models. Communications in Statistics - Theory and Methods. 1991;20(8):2609-2631.

21. Bernier MO, Leenhardt L, Hoang C, et al. Survival and therapeutic modalities in patients with bone metastases of differentiated thyroid carcinomas. J Clin Endocrinol Metab. 2001;86(4):1568-1573.
22. Pittas AG, Adler M, Fazzari M, et al. Bone metastases from thyroid carcinoma: clinical characteristics and prognostic variables in one hundred forty-six patients. Thyroid. 2000;10(3):261-268.

\section{Publish your work in this journal}

Comparative Effectiveness Research is an international, peer reviewed open access journal focusing on comparative effectiveness of health care including preventative health care strategies, diagnostic strategies, diagnostic technology, medical devices, drugs, medical technology, health systems and organization. The manuscript management system is completely online and includes a very quick and fair peer-review system. Visit http://www.dovepress.com/testimonials.php to read real quotes from published authors.

\footnotetext{
Submit your manuscript here: http://www.dovepress.com/comparative-effectiveness-research-journal
} 